\title{
Evanghélia Stead, La Chair du livre. Matérialité imaginaire et poétique du livre fin-de-siècle
}

\section{Ida Merello}

\section{(2) OpenEdition}

1 Journals

\section{Edizione digitale}

URL: https://journals.openedition.org/studifrancesi/3182

DOI: 10.4000/studifrancesi.3182

ISSN: 2421-5856

\section{Editore}

Rosenberg \& Sellier

\section{Edizione cartacea}

Data di pubblicazione: 1 juillet 2013

Paginazione: 481-482

ISSN: 0039-2944

\section{Notizia bibliografica digitale}

Ida Merello, «Evanghélia Stead, La Chair du livre. Matérialité imaginaire et poétique du livre fin-de-siècle», Studi Francesi [Online], 170 (LVII | II) | 2013, online dal 30 novembre 2015, consultato il 02 février 2023 URL: http://journals.openedition.org/studifrancesi/3182 ; DOI: https://doi.org/10.4000/studifrancesi. 3182

Questo documento è stato generato automaticamente il 2 février 2023.

\section{(c) 9 (1) $\Theta$}

Creative Commons - Attribuzione - Non commerciale - Non opere derivate 4.0 Internazionale - CC BYNC-ND 4.0

https://creativecommons.org/licenses/by-nc-nd/4.0/ 


\title{
Evanghélia Stead, La Chair du livre. Matérialité imaginaire et poétique du livre fin-de-siècle
}

\author{
Ida Merello
}

\section{NOTIZIA}

EVANGHÉLIA STEAD, La Chair du livre. Matérialité imaginaire et poétique du livre fin-de-siècle, Paris, PUPS 2012, pp. 566.

1 Un libro sulla sensualità dei libri illustrati della fin de siècle ottocentesca non poteva forse altrimenti riproporne la sensualità e la suggestione che questa specie di libro strenna, in preziosa carta lucida al servizio delle immagini. Mobili, dettagli di legno scolpito, statue, riproduzione di pagine di riviste e di romanzi con le loro vignette, affiches, ex-libris, ma anche fumetti, illustrazioni e fotografie dei tempi nostri che ripropongono miti della decadenza, come Salomé, o citazioni preziose di vecchie tele, sono sgranati nel corso delle pagine. Il ruolo fondamentale delle arti visive all'interno delle edizioni di fine Ottocento viene dimostrato così innanzitutto grazie a un aspetto formale pre-verbale, che su queste edizioni si modella, suggerendo lo stesso piacere sensuale. La sensualità del toccare e del guardare si accompagna così a un approccio critico sulla semiologia, l'analisi dei testi, la poetica e l'immaginario, per la messa a punto di un vocabolario estetico nuovo in cui la fine secolo si lega strettamente alla modernità.

2 L'opera è divisa in cinque parti, precedute da un preambolo e un epilogo, e si organizza intorno allo statuto dell'immagine, il ruolo degli artisti all'interno dei libri, l'elaborazione della femme fatale attraverso le figure di Salomé e di Cleopatra, il topos della donna lettrice, per concludersi con l'immaginario del libro nella finzione letteraria e il superamento della forma/libro in manufatto artistico (ad esempio il libro ventaglio). Evanghélia Stead aggiunge una voluminosa bibliografia suddivisa per 
argomenti e autori e un complesso indice tematico. Proprio questo indice lascia intendere una complicità tra l'A. e il lettore, che è invogliato dallo stesso piacere di sfogliare l'opera a non leggerla di seguito, ma a inseguire centri di interesse, procedendo avanti e indietro, leggendo insieme il testo della Stead, i testi fotografati nelle loro belle edizioni, e guardando le figure. 